\title{
PENGARUH SENAM HAMIL TERHADAP PENURUNAN TINGKAT NYERI PUNGGUNG BAWAH PADA IBU HAMIL TM III DIWILAYAH KERJA PUSKESMAS JEMBATAN KECIL
}

\author{
Ruri Maiseptya Sari ${ }^{1}$, Yuni Ramadhaniati ${ }^{2}$, Desti Indaryani ${ }^{3}$ \\ STIKES Tri Mandiri Sakti Bengkulu Jurusan Kebidanan ${ }^{123}$ \\ Email:1'Rury_maiseptyasari@yahoo.com
}

\begin{abstract}
This research aims to determine the effect of pregnant gymnastics on lower back pain levels of pregnant women at TM III in the workplace Puskesmas small bridge year 2019.

This research uses Pre experimental design type one group control Pretest And Posttest Design. The population in this study is all TM III expectant mothers in small bridge Puskesmas area as much as 20 people. The data collection techniques in this study use primary data and secondary data.Data analysis using independent statistical test T-Test. The results showed that there was a influence of pregnant gymnastics on the decline in lower back pain levels in the trimester III of pregnant women. Before the pregnant gymnastics 15 mothers who experienced moderate pain and 5 mothers experienced very painful., whereas after pregnant gymnastics 12 mothers who experience moderate pain and 8 mothers experience little pain. Therefore it can be concluded that there is a influence of pregnant gymnastics on the decline of lower back pain levels in the trimester III of pregnant women.
\end{abstract}

Key Words: Pregnant gymnastics, lower back pain, trimester III pregnant women

\section{ABSTRAK}

Penelitian ini bertujuan untuk mengetahui Pengaruh Senam Hamil Terhadap Penurunan Tingkat Nyeri Punggung Bawah Pada Ibu Hamil TM III di wilayah kerja puskesmas Jembatan kecil Tahun 2019. Penelitian ini menggunakan desain Pre Eksperimental tipe one group control Pretest And Posttest Design. Populasi dalam penelitian ini adalah semua ibu hamil TM III di Wilayah Puskesmas Jembatan Kecil sebanyak 20 orang. Teknik pengumpulan data dalam penelitian ini menggunakan data primer dan data sekunder. Analisis data menggunakan uji statistik independen t-test. Hasil penelitian menunjukan bahwa terdapat pengaruh senam hamil terhadap penurunan tingkat nyeri punggung bawah pada ibu hamil trimester III. Sebelum diberikan senam hamil 15 ibu yang mengalami nyeri sedang dan 5 ibu mengalami sangat nyeri., sedangkan setelah diberikan senam hamil 12 ibu yang mengalami nyeri sedang dan 8 ibu mengalami sedikit nyeri. oleh sebab itu dapat disimpulkan bahwa Ada pengaruh senam hamil terhadap penurunan tingkat nyeri punggung bawah pada ibu hamil trimester III.

Kata kunci: Senam hamil, nyeri punggung bawah, ibu hamil trimester III

PENDAHULUAN
Masa kehamilan merupakan masa dimana ibu akan mengalami perubahan fisik 
maupun psikis. Perubahan fisik yang terjadi bahkan kadang memberikan ketidaknyamanan bagi ibu, salah satunya adalah nyeri punggung bagian bawah. Nyeri punggung bawah pada wanita hamil terjadi pada kehamilan trimester III yang berkaitan dengan peningkatan berat badan akibat pembesaran rahim dan peregangan dari otot penunjang, karena hormon relaksan (hormon yang membuat otot relaksasi dan lemas) yang dihasilkan (Triyana, 2013).

Salah satu cara untuk mengurangi ketidaknyamanan tersebut adalah dengan melakukan senam hamil. Senam hamil merupakan terapi latihan gerak yang diberikan pada ibu hamil untuk mempersiapkan dirinya baik fisik maupun mental, senam hamil dapat meringankan nyeri punggung bawah yang dirasakan ibu hamil karena didalam senam hamil terdapat gerakan yang dapat memperkuat otot abdomen, membuat elastisitas otot dan ligamen yang ada di punggung dan relaksasi, sehingga senam hamil dapat menurunkan nyeri punggung bagian bawah (Yosefa dkk, 2011).

Berdasarkan hasil data Dinas kesahatan Kota Bengkulu tahun 2018 yang didapatkan ibu hamil TM III biasanya melakukan kunjungan pada $\mathrm{K} 4$ ada tiga puskesmas tertinggi kunjungan K4 pada tahun 2018 yaitu puskesmas basuki rahmat sebanyak 629 dan sebanyak $77,7 \%$ yang melakukan kunjungan K4, Puskesmas Jembatan Kecil 487 yang melakukan kunjungan k4 76,5\%, dan yang terendah adalah Puskesmas Nusa Indah yang melakukan kunjungan $\mathrm{k} 4$ dari 4438 sebanyak 84,7\% Dari ketiga puskesmas tersebut yang melakukan senam hamil yaitu Puskesmas Jembatan kecil dan merupakan Puskesmas nomor dua terbanyak kunjungan K4 ( Dinkes kota Bengkulu Tahun 2018 ).

Menurut hasil data yang dilihat dari buku register kunjungan ibu hamil di
Puskesmas Jembatan kecil, jumlah ibu hamil Di Puskesmas Jembatan Kecil dari bulan Januari sampai November 2019 didapatkan ibu hamil TM III sebanyak 165 orang dan dengan keluhan Nyeri punggung dan melakukan senam hamil sebanyak 105 orang ( Buku Register KIA Puskesmas Jembatan Kecil ).

Berdasarkan survey awal yang dilakukan peneliti pada tanggal 30 november 2019 di wilayah kerja Puskesmas jembatan kecil dengan mewawancarai 5 ibu hamil, ditemukan bahwa 3 diantaranya mengalami nyeri punggung yang sangat mengganggu saat menjalani aktivitasnya dan 2 ibu hamil mengeluhkan nyeri punggung tapi tidak sampai mengganggu aktivitas. Upaya yang dilakukan untuk mengurangi nyeri tersebut yaitu dengan memijat punggungnya dengan minyak kayu putih, istirahat, dan ada juga yang mengompres punggungnya dengan air hangat. Saat ditanya mengenai aktivitas olahraga seperti senam hamil 3 ibu hamil menjawab pernah melakukan kegiatan tersebut tetapi tidak teratur dan 2 diantaranya tidak pernah melakukan senam hamil.

Rumusan Masalah dalam penelitian ini adalah Apakah ada pengaruh senam hamil terhadap penurunan tingkat nyeri punggung bawah pada ibu hamil trimester III di wilayah kerja Puskesmas Jembatan Kecil kota Bengkulu tahun 2019 ?. Tujuan dari penelitian ini adalah Mengatahui pengaruh senam hamil terhadap penurunan nyeri punggung bawah pada ibu hamil trimester III di wilayah kerja Puskesmas Jembatan Kecil kota Bengkulu tahun 2019.

\section{METODE PENELITIAN}

Jenis penelitian ini pre eksperimental one group pre test and post test. Penelitian menggunakan desain penelitian yang berbentuk one group pretest-possttest design yaitu tidak ada kelompok 
pembanding (control). Populasi yan dalam penelitian ini adalah selu hamil yang mengalami nyeri $\mathrm{pl}$ Valid Sedikit Nyeri bawah di wilayah kerja pu Jembatan Kecil pada bulan JanuariNyeri sedang 2020. Pengambilan sampel dalam $p$

Total

Frequency Percent Valid Percent Percent ini menggunakan tekhnik total sampling sebanyak 20 orang. Penelitian ini menggunakan data primer data sekunder. Analisis data dilakukan secara univariat, bivariate dengan menilai skala nyeri menngunakan Numeral Rating Scale (NRS) dan Uji T-test.

\begin{tabular}{rrrr}
8 & 40.0 & 40.0 & 40.0 \\
\hline 12 & 60.0 & 60.0 & 100.0 \\
\hline 20 & 100.0 & 100.0 &
\end{tabular}

Dari tabel 2. diatas diketahui bahwa dari 20 ibu hamil TM III setelah dilakukan kelas ibu hamil terdapat $12 \mathrm{ibu}$ yang mengalami nyeri sedang dan $8 \mathrm{ibu}$ mengalami sedikit nyeri

\section{Analisis Bivariat}

\section{HASIL PENELITIAN}

\section{Analisis Univariat}

Analisis univariat yang di analisis dalam penelitian ini adalah menggambarkan intensitas nyeri pada responden sebelum dan sesudah melakukan senam hamil. Caranya adalah responden menggunakan alat pendeskripsi kata.

Anailsis bivariat dalam penelitian ini dilakukan untuk mengetahui pengaruh senam hamil terhadapan penurunan nyeri punggung bawah pada ibu hamil TM III di Puskesmas jembatan Kecil kota Bengkulu adapun uji yang digunakan adalah uji $\mathrm{T}$, yang dapat dilihat pada tabel berikut:

Tabel 3. Uji Normalitas Pengaruh

Table 1. Distribusi frekuensi intensitas nyeri punggung bawah sebelum dilakukan senam hamil pada ibu hamil trimester III Di Puskesmas Jembatan Kecil

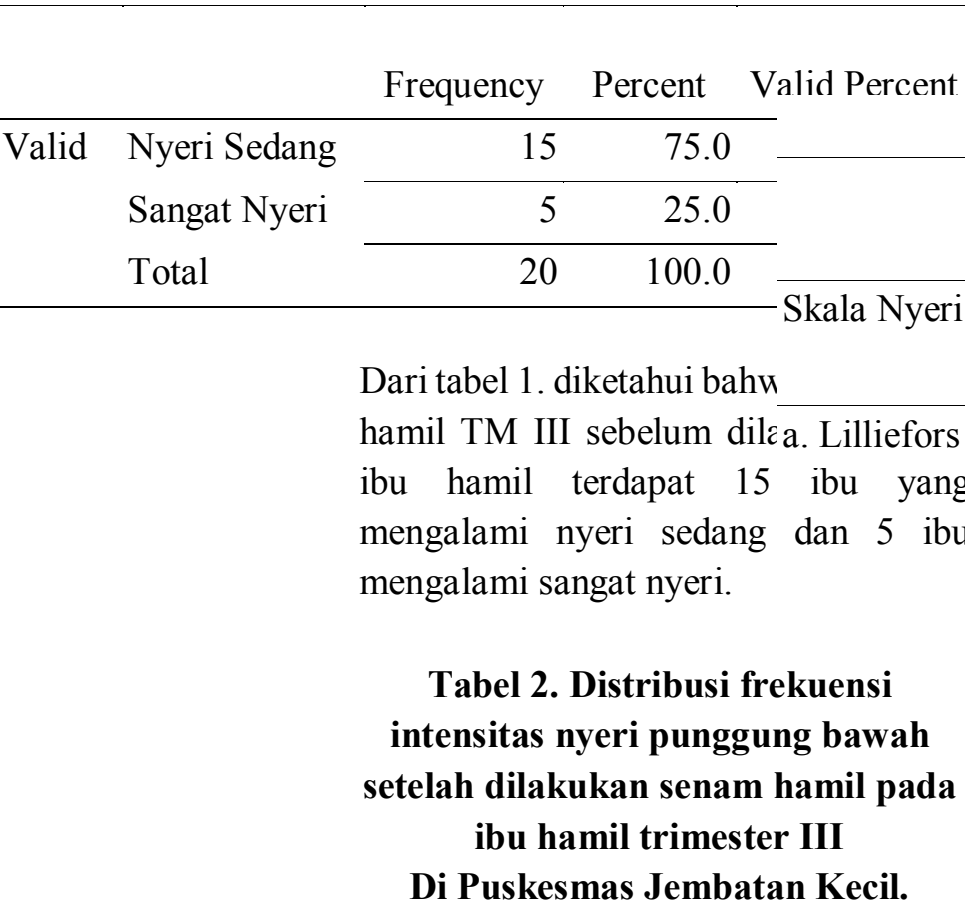

Senam hamil terhadap penurunan tingkat nyeri punggung bawah pada ibu hamil TM III

Puskesmas Jembatan Kecil Kota

Bengkulu.

\section{Cumulative}

Percent

\section{Cumulative} 0.0 
tergolong seseorang yang berpendidikan yg tidak rendah, mereka menganggap bahwa senam hamil merupakan senam yang baik untuk dilakukan, biasanya senam hamil tidak dilakukan karena kurangnya ilmu pengetahuan baru dan pola pikir serta anggapan masyarakat yang kurang untuk memahami senam hamil.

Berdasarkan data yang diperoleh menunjukkan sebagian besar dari responden bekerja sebagai IRT yaitu 14 responden .Menurut peneliti responden yang berstatus sebagai IRT memiliki tanggung jawab yang penuh untuk mengurus keluarga sehingga banyak melakukan aktivitas fisik yang berlebihan, selain itu pengalaman dan ilmu yang diperoleh akan lebih sedikit, rasa ingin tahu akan ilmu baru pun rendah.

Berdasarkan data umum yang diperoleh dari responden menunjukkan seluruh responden usia kehamilannya 7-9 bulan yaitu 20 responden. Menurut peneliti pada kehamilan trimester III ibu lebih banyak mengalami nyeri punggung bawah dibandingkan pada kehamilan trimester II dikarenakan seiring bertambahnya usia kehamilan perubahan postur tubuh ibu cenderung mengalami perubahan seperti lordosis, nyeri punggung bawah akan lebih meningat jika ibu tidak pernah melakukan aktifitas fisik untuk mengurangi keluhan nyeri punggung bawah.

Berdasarkan Berdasarkan data umum yang diperoleh dari responden menunjukkan sebagian besar dari responden pernah melakukan senam hamil yaitu 14 responden dan yang tidak pernah melakukan senamhamil sebanyak 6 responden. Menurut peneliti di Puskesmas Jembatan Kecil sudah diadakan kelas ibu hamil setiap periode tertentu, pada periode atau gelombang ini ibu hamil sudah diberikan materi senam hamil.

Berdasarkan data umum yang diperoleh dari responden menunjukkan sebagian besar dari responden pernah mendapatkan informasi tentang senam hamil yaitu $17 \mathrm{ibu}$ hamil dan 3 ibu hamil tidak pernah mendapatkan informasi tentang senam hamil. Menurut peneliti informasi sangat penting dalam kehidupan karena dapat mempengaruhi sesorang dalam bertingkah laku, semakin sedikit informasi yang didapatkan maka kemampuan dalam memotivasi akan semakin rendah, sebaliknya semakin banyak informasi yang didapat tentang senam hamil akan semakin baik. Karena dengan informasi sesorang akan lebih mengerti, memahami dan mampu melakukan tindakan yang seharusnya dilakukan serta menghindari tindakan yang dapat merugikan diri sendiri dan bayinya.

Berdasarkan data umum yang diperoleh dari responden menunjukkan lebih dari setengah dari responden pernah mendapatkan informasi tentang nyeri punggung bawah yaitu 13 ibu hamil dan 7 ibu hamil tidak pernah mendapatkan informasi tentang nyeri punggung bawah. Menurut peneliti informasi sangat penting dalam kehidupan karena dapat mempengaruhi sesorang dalam bertingkah laku, semakin sedikit informasi yang didapatkan maka kemampuan dalam memotivasi akan semakin rendah, sebaliknya semakin banyak informasi yang didapat tentang senam hamil akan semakin baik. Karena dengan informasi sesorang akan lebih mengerti, memahami dan mampu melakukan tindakan yang seharusnya dilakukan serta menghindari tindakan yang dapat merugikan diri sendiri dan bayinya.

Berdasarkan tabel 4 menunjukkan sebagian besar ibu hamil trimester III mengalami nyeri punggung bawah dengan rata-rata skala 4 (nyeri sedang) yaitu ketika sedang mengalami nyeri punggung pasien mendesis, menyeringai, tetapi masih dapat menunjukkan lokasi nyeri , dapat mendeskripsikannya, dan masih dapat mengikuti perintah dengan baik sebanyak 12 ibu hamil $(60,0 \%)$ dan sebanyak 8 ibu hamil (40,0\%) mengalami nyeri punggung bawah dengan rata-rata skala 3 (sedikit nyeri) yaitu pasien masih dapat berkomunikasi dengan baik tapi hanya 
merasakan kram sedikit dibagian punggung.

Menurut peneliti senam hamil dapat mengurangi nyeri punggung bawah pada ibu hamil trimester III. Dengan durasi senam hamil selama 15 menit minimal 3-4 kali dalam sebulan dan dilakukan 2 kali dalam seminggu dan harus dilakukan sesuai SOP sehingga bisa dirasakan manfaat secara maksimal dan ibu bisa nyaman menjalani kehamilannya.

\section{KESIMPULAN DAN SARAN}

Terdapat pengaruh yang bermakna antara pelaksaan senam hamil terhadap penurunan tingkat nyeri punggung bawah pada ibu hamil trimester III di Puskesmas Jembatan Kecil kota Bengkulu.

Diharapkan kepada lahan praktik untuk menjadi wadah serta fasilitator bagi ibu bersalin dalam menghadapi proses persalinan yang nyaman dan menyenangkan dalam melewati kala I yang lebih singkat.

\section{DAFTAR PUSTAKA}

1. Dinas Kesehatan Kota Bengkulu. (2018). Profil Dinas Kesehatan Kota Bengkulu tahun 2018. Bengkulu : Dinkes Kota Bengkulu

2. Dinas Kesehatan provinsi Bengkulu. (2017). Profil Dinas Kesehatan Provinsi Bengkulu tahun 2017. Bengkulu : Dinkes Provinsi Bengkulu

3. Dinas Kesehatan Provinsi Bengkulu. (2018). Profil Dinas Kesehatan Provinsi Bengkulu tahun 2018. Bengkulu : Dinkes Provinsi Bengkulu

4. Fitriani,Lina.(2018). Efektivitas senam hamil dan yoga hamil terhadap penurunan nyeri punggung pada ibu hamil trimester III di Puskesmas Pekkabata : Jurnal kesehatan masyarakat Vol.4, No.2, November 2018 (Diakses 10 november 2019)

5. Kemenkes. Rencana Strategis Kementerian Kesehatan Tahun 20152019. Jakarta: Kementerian Kesehatan RI; 2015.

6. Hakiki, 2015. Nyeri Tulang Belakang Selama Kehamilan.(di akses pada tanggal
8 desember 2019) dari :http://forikesejournal.com

7. Harsono, T. 2013. Permasalahan Kehamilan yang Sering Terjadi. Yogyakarta : Platinum

8. Indaryani. (2011). Buku Ajar Asuhan Kehamilan. Bandung : CV. Trans Info Media

9. Mafikasari, A. \& Kartikasari, R. A. (2015). Posisi Tidur Dengan Kejadian Back Pain (Nyeri Punggung) Pada Ibu Hamil Trimester III. Vol. 07, No. 02. Hal. 26.

10. Manuaba, I.B.G, dkk. 2013. Ilmu Kebidanan, Penyakit Kandungan dan KB. Jakarta : CV. Trans Info Media.

11. Maryunani, Anik, dan Yetty Sukaryati. 2011. Senam Hamil, Senam Nifas, dan Terapi Musik. Jakarta : Trans Info Medika

12. Notoatmodjo. 2010. Metodologi Penelitian Kesehatan. Jakarta : Rinela Cipta.

13. Nursalam, 2015. Metodologi Penelitian Ilmu Keperawatan Pendekatan Praktis, Edisi 3. Jakarta: Salemba Medika.

14. Nursalam. 2016. Metodologi Penelitian Ilmu Keperawatan, Pendekatan Praktis, Edisi 4. Jakarta : Salemba Medika.

15. Nugroho, $\mathrm{T}$ (2014) Ginekologi dan Obstetri (OBSGYN), Yogyakarta : Nuha Medika

16. Nurhudhariani, R, Febriyanti, SNU, Putri, VTA (2015). Pengaruh Pelatihan Senam Hamil terhadap Peningkatan Ketrampilan Senam Hamil di Wilayah Kerja Puskesmas Kedungmundu Semarang. Semarang : STIKES Karya Husada. Diakses pada tanggal 10 oktober 2019

17. Perry \& Potter. 2015. Buku Ajar Keperawatan Medika Bedah. Edisi 8 volume 2. Jakarta : EGC

18. Prasetyo, 2010. Konsep dan Proses Keperawatan Nyeri. Yogyakarta: Nuha Medika.Prawirohardjo, Sarwono, 2014. Ilmu Kebidanan (4ed). Jakarta : PT Bina Pustaka

19. Sugiyono, 2012. Metode Penelitian Kuantitatif dan R\&D. Bandung : Alfabeta

20. Sulastri. (2012) Senam Hamil Bantu Melahirkan Tanpa Kecemasan. Profesi Volume 8.

21. Triyana, Y. 2013. Panduan Klinis Kehamilan Dan Persalinan. Jogjakarta: 
DMedika.

22. Wagey, F.W. 2011. Senam Hamil Meningkatkan Antioksidan Enzimatik, Kekuatan Otot Panggul, Kualitas Jasmani dan Menurunkan Kerusakan Oksidatif pada Wanita Hamil. Disertasi tidak diterbitkan. Denpasar: Program Pascasarjana Universitas Udayana.

23. Widiyawati, dan Fariani, S (2013) Pengaruh Senam Hamil Terhadap Proses Persalinan dan Status Kesehatan Neonatus. Jurnal Berkala Epidemiologi Vol.1.2: 316-324.

24. Yosefa, Febriana et all. 2013. Efektifitas
Senam Hamil Terhadap Penurunan Nyeri Punggung Pada Ibu Hamil Jurnal Online Keperawatan, Vol 1, No.1. (2014), http : / / jom . ac . id / index . php / JOMSIK / article / views / 3537 /3432 (diakses tanggal 25 November 2019)

25. Yuliasari. 2010. Hubungan Pengetahuan dan Sikap dengan Pelaksanaan Senam Hamil (Studi pada Ibu Hamil Timester II dan III) di Puskesmas Ciputat.

26. Yuliani, Retno D,dkk.(2017). Buku Ajar Aplikasi Asuhan Kehamilan. Jakarta Timur : CV.Trans Info Madia 